https://doi.org/10.15407/ujpe65.4.336

I. OVSIIENKO,${ }^{1}$ T. LEN,${ }^{1}$ L. MATZUI, ${ }^{1}$ O. SYVOLOZHSKYI,${ }^{1}$ D. SHPYLKA,${ }^{1}$

D. NAUMOVA ${ }^{2}$

1 Taras Shevchenko National University of Kyiv, Faculty of Physics

(60, Volodymyrs'ka Str., Kyiv 01601, Ukraine)

2 Taras Shevchenko National University of Kyiv, Faculty of Chemistry

(60, Volodymyrs'ka Str., Kyiv 01601, Ukraine)

\title{
INFRARED SPECTROSCOPY OF ULTRAVIOLET-IRRADIATED CARBON NANOTUBES ${ }^{1}$
}

\begin{abstract}
The possibility of using the UV irradiation for a functionalization of carbon nanotubes with different degrees of structural perfection is considered. In investigations, the method of infrared spectroscopy is used. A change in the number of functional groups under the short-term UV irradiation of specimens with multiwall carbon nanotubes is estimated by a change in the relative intensity of the IR spectral bands corresponding to vibrations of the functional groups in comparison with the relative intensity of the band corresponding to vibrations of the carbon atoms in graphite.

Ke ywords: multiwall carbon nanotubes, infrared spectroscopy, ultra violet irradiation.
\end{abstract}

\section{Introduction}

The development of new composite materials based on polymer matrices with nanocarbon filler, in particular, multiwall carbon nanotubes (MWCNTs), is one of the main tasks of modern materials science. When creating the composite materials, it is important to consider their temporal stability and mechanical strength under the influence of various external factors. This is achieved, firstly, by the formation of a homogeneous dispersion of the nanocarbon filler in the polymeric matrix, and, secondly, by a strong bond between the filler particles and the polymeric matrix. The problem is further complicated by the fact that all nanocarbon particles are hydrophobic. As is known, the method of functionalization of a nanocarbon filler surface can be used for the solution of this problem. The functionalization of a nanocarbon surface creates favorable conditions for the uniform dis-

(C) I. OVSIIENKO, T. LEN, L. MATZUI,

O. SYVOLOZHSKYI, D. SHPYLKA,

D. NAUMOVA, 2020 tribution of a nanocarbon filler in the polymer matrix and provides the strong connection between filler particles and the polymer matrix [1-3]. The most common method to obtain functional groups on the surface of a nanocarbon filler is the covalent functionalization. At the covalent functionalization, the destruction of the delocalized $\pi$-electron system and the partial $\sigma$-bond break in the graphite layer occur, thus forming the free bonds, due to which various functional groups are joined with carbon atoms on the surface of carbon nanotubes (CNTs) [4-7]. Thus, the covalent functionalization causes the formation of a significant number of defects on the surface of CNTs. This process, on the one hand, improves the connection between a nanocarbon filler and the polymeric matrix and enhances the mechanical properties of nanocomposites. On the other hand, a significant number of defects in the nanocarbon filler re-

\footnotetext{
1 The paper was presented at XXIVth Galyna Puchkovska International School-Seminar "Spectroscopy of Molecules and Crystals" (August 25-30, 2019, Odesa, Ukraine).
} 
sults in a deterioration of its properties associated with charge transfer. This causes a deterioration of the electrical properties of the polymeric composite as a whole. Another method used to obtain functional groups on the surface of the nanocarbon filler is the noncovalent functionalization [8-11]. The noncovalent functionalization does not lead to the destruction of the $\mathrm{sp}^{2}$-graphite structure, i.e., the unique properties of a nanocarbon filler are kept. However, the weak bonds between carbon atoms and functional groups provide no strong interfacial interaction between a nanocarbon filler and the polymer matrix, which significantly impairs primarily the mechanical properties of polymer nanocomposites. Therefore, the search for optimal methods of nanocarbon surface functionalization is very important. From this point of view, the use of a short-term UV irradiation can be very useful, because the short-term UV irradiation does not lead to the destruction of the filler structure.

The aim of the presented work was to establish the possibility of using the UV irradiation for a functionalization of CNTs with different degrees of structural perfection. The study is conducted by the method of infrared (IR) spectroscopy.

\section{Experimental}

For the studies, two specimens of CNTs with different degrees of structural perfection have been chosen.

Specimen \#1 is MWCNTs obtained by the method of catalytic decomposition of a hydrocarbon in the presence of a nickel catalyst. According to the passport data, specimen $\# 1$ contains $\sim 80 \%$ of MWCNTs with diameters up to $50 \mathrm{~nm}$ and lengths up to $10 \mathrm{mcm}, \sim 15 \%$ of the disordered carbon phase, and a small amount of the catalyst.

Specimen \#2 is MWCNTs obtained by the method of catalytic decomposition of a hydrocarbon in the presence of an iron catalyst and purified by the thermochemical method. According to the passport data, this specimen contains $~ 99 \%$ MWCNTs with diameters up to $50 \mathrm{~nm}$ and lengths up to $10 \mathrm{mcm}$ and $\sim 1 \%$ of the disordered carbon phase.

The structure of MWCNTs was investigated by the $\mathrm{X}$-ray diffraction method on an X-ray diffractometer DRON 4-07 (with $\mathrm{Ni}_{K \alpha}$ radiation for specimen \#1 and $\mathrm{Co}_{K \alpha}$ radiation for specimen $\# 2$ ).

The specimens of MWCNTs were exposed to the UV-irradiation by a DRT-1000 (ultraviolet lamp) equipped with an electric-discharge arc high-pressure lamp inflated with mercury and argon compound that could release the ultraviolet radiation $50 \mathrm{~W}$ in power at a wavelength of 240-320 nm. The distance between a UV lamp and the sample was fixed at $11 \mathrm{~cm}$.

The quantitative composition of functional groups on the surface of the source and UV irradiated CNTs is determined by the IR spectroscopy method. The experiments have been performed by a Perkin Elmer Spectrum BX FT-IR infrared spectrometer in the frequency range $4000-400 \mathrm{~cm}^{-1}$. The specimens in a form of pellets $10 \mathrm{~mm}$ in diameter were prepared from a powder mixture of pre-dried CNTs and $\mathrm{KBr}$.

\section{Results and Discussion}

Figure 1 presents the fragments of X-ray diffraction patterns for specimen $\# 1$ (Fig. 1, a) and specimen \#2 (Fig. 1, b).

As is seen from Fig. 1, the diffraction patterns for specimens $\# 1$ and $\# 2$ are different. For specimen $\# 1$, the X-ray diffraction pattern contains only intense $00 l$ graphite bands. The interlayer distance determined from the angular position of the $00 l$ lines according to the Bragg law is $0.340 \mathrm{~nm}\left(d_{002}=0.340 \mathrm{~nm}\right)$. The size of crystallites $L$ for MWCNTs of specimen \#1 was estimated by the broadening of 002-band according to the relation

$L=\frac{k \lambda}{\beta \cos (\theta)}, \quad \beta=\sqrt{B^{2}-b^{2}}$,

where $k$ is the band form-factor, $k=0.90, \lambda$ is the $\mathrm{X}$ ray wavelength, $\theta$ is the angle at which the band is observed, $B$ is the band half-width for the test specimen, and $b$ is the band half-width for the reference specimen. As the reference specimen, natural monocrystalline graphite was used. The crystallite size $L$ for specimen \#1 determined according to relation (1) is $\sim 20 \mathrm{~nm}$. In addition, the intense band corresponding to the nickel catalyst is observed for specimen $\# 1$.

Unlike specimen \#1, there are $00 l(002,004)$ graphite bands and $h k l(100,101)$ graphite bands on the X-ray diffraction pattern for specimen $\# 2$. The angular position of the $00 l$ bands corresponds to the interplanar distance $d_{002}=0.3354 \mathrm{~nm}$. This $d_{002}$ value is equal to the interplanar distance in monocrystalline graphite. The presence of the 100 and 101 graphite bands in the X-ray diffraction pattern indicates a certain ordering of the graphite planes in the MWCNTs among themselves. The crystallite size 


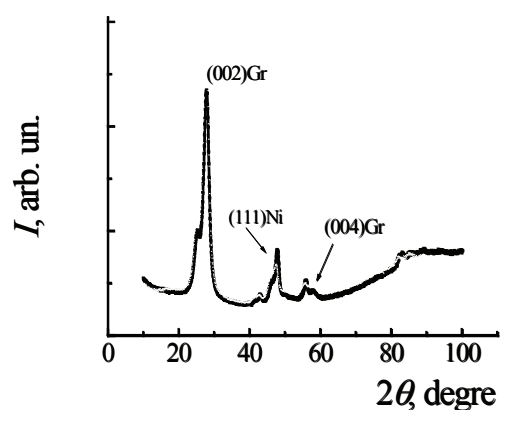

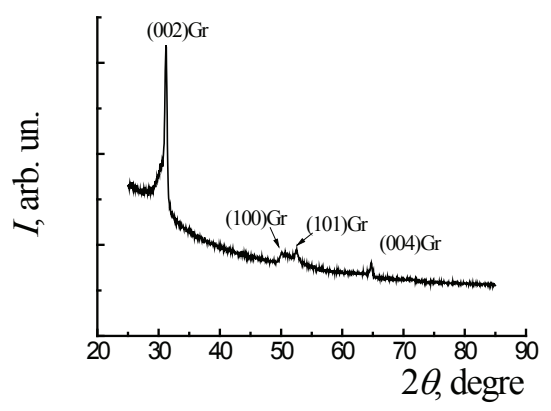

$b$

Fig. 1. The fragments of X-R diffraction patterns for specimen $\# 1(a)$ and specimen $\# 2(b)$

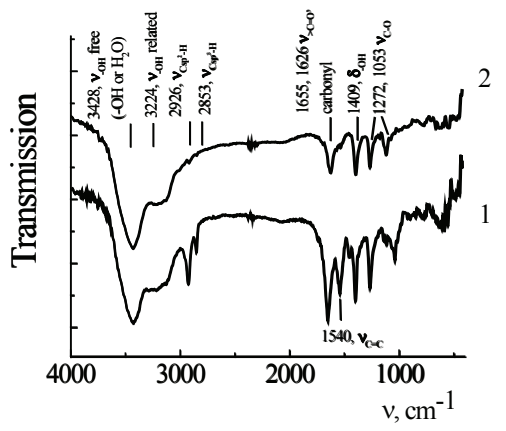

$a$

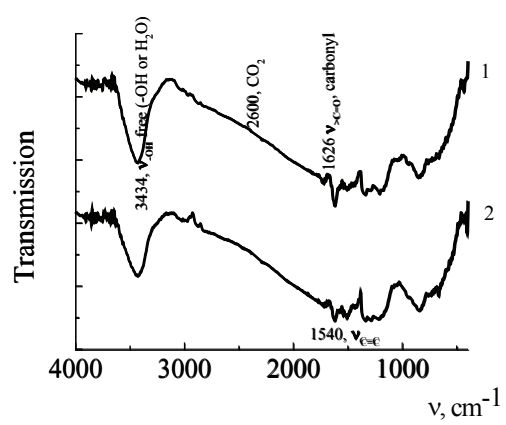

$b$

Fig. 2. The fragments of IR spectra for specimens \#1 (a) and \#2 (b) before (1) and after (2) UV irradiation

$L$ for specimen \#2 was estimated by the broadening of $h k l$-bands with the use of relation (1) in which $k=1.84$. The calculations give the value $L \sim 65 \mathrm{~nm}$. As seen from Fig. $1, b$, for specimen $\# 2$, the catalyst bands are absent on the X-ray diffraction pattern.

Therefore, according to X-ray diffraction investigations, specimen $\# 1$ is MWCNTs for which a constant distance between graphite layers is observed with no ordering between the individual graphite layers. The graphite layers themselves contain a significant amount of defects, as indicated by the relatively small crystallites size. Specimen \# 2 is MWCNTs, and the distance between its layers corresponds to the distance between the graphite layers in HOPG. There is some ordering between the graphite layers for specimen $\# 2$, and the graphite layers are less defective than for specimen $\# 1$.

The specimens of MWCNTs were exposed to the short-term ultraviolet irradiation. The fragments of the IR spectra for the MWCNTs specimens \#1 $(a)$ and $\# 2$ (b) before (1) and after irradiation (2) are shown in Fig. 2. As is shown in Fig. 2, $a$, IR spectra are significantly different for the source and UVtreated specimen $\# 1$. The spectrum for specimen \#1 contains both bands corresponding to vibrations of the functional groups, as well as the intense bands associated with vibrations of the carbon atoms on the CNTs surface; moreover, the intensities of these bands are approximately equal. In the IR spectra for UV-irradiated specimen $\# 1$, the intensity of bands corresponding to vibrations of carbon atoms is negligible compared to those of the bands of functional groups.

Let us analyze the spectra of the source and UVirradiated MWCNTs for specimen \#1 in more details. The most intense bands in the IR-spectra for both specimens are associated with valence vibrations of the hydroxyl group $\nu_{-\mathrm{OH}}$. Each of these bands has two components. The first $\left(3428 \mathrm{~cm}^{-1}\right)$ more intense component corresponds to adsorbed water (tabular value $3400 \mathrm{~cm}^{-1}$ ) or valence vibrations of the so-called free groups $-\mathrm{OH}$. These groups are 
not parts of other functional groups, for example, the carboxyl group - $\mathrm{COOH}$. The second less intense component corresponds to vibrations of the related groups $-\mathrm{OH}$, that is, those that are parts of other functional groups. The following two bands (more intense at $2926 \mathrm{~cm}^{-1}$ and less intense at $\left.2853 \mathrm{~cm}^{-1}\right)$ are associated, respectively, with valence vibrations of $\operatorname{sp}^{2}\left(\nu_{\mathrm{Csp}^{2}-\mathrm{H}}\right)$ and $\mathrm{sp}^{3}\left(\nu_{\mathrm{Csp}^{3}-\mathrm{H}}\right)$ hybridized carbon atoms related to hydrogen. Such carbon atoms with attached hydrogen, including the rehybridized $\mathrm{sp}^{3}$ carbon atoms, are located along the boundaries of crystallites. Thus, the presence of these intense lines can be considered as a criterion of the perfection of the nanocarbon structure. One more band associated with valence vibrations of the graphite skeleton is the $\mathrm{C}=\mathrm{C}$ band $\left(\nu_{\mathrm{C}=\mathrm{C}}, 1540 \mathrm{~cm}^{-1}\right)$. As can be seen from Fig. 2, the intensity of this band for the source specimen $\# 1$ is approximately equal to the intensity of the $\mathrm{C}_{\mathrm{sp}^{2}-\mathrm{H}}$ and $\mathrm{C}_{\mathrm{sp}^{3}-\mathrm{H}}$ bands, as well as the intensities of the bands corresponding to the different functional groups. Another intense band in the spectrum of the source MWCNTs of specimen \#1 corresponds to the valence vibrations of the carbonyl group $\left(\nu_{>\mathrm{C}=\mathrm{O}}, 1626 \mathrm{~cm}^{-1}\right)$. The next band $\left(1409 \mathrm{~cm}^{-1}\right)$ is associated with the deformation vibrations of the hydroxyl group $\left(\delta_{-\mathrm{OH}}\right)$. Note that the intensity of this band correlates with the intensity of the valence vibration band $\left(\nu_{-\mathrm{OH}}\right)$. The last broad intense band containing at least two components is associated with the valence vibrations of the functional group $\mathrm{C}-\mathrm{O}\left(\nu_{-\mathrm{C}-\mathrm{O}}\right)$, which is a part of, in particular, the lactone groups or ethers.

As can been seen from Fig. 2, $b$, the shapes of the IR spectra for the source and UV- treated specimen $\# 2$ are almost the same, unlike specimen \#1. For the source and UV-treated specimen $\# 2$, the $\nu^{\prime} \mathrm{C}=\mathrm{C}$ band $\left(1540 \mathrm{~cm}^{-1}\right)$ corresponding to vibrations of the graphite skeleton is observed in the IR spectra. In addition, $\nu_{-\mathrm{Csp}^{2}-\mathrm{H}}$ and $\nu_{-\mathrm{Csp}^{3}-\mathrm{H}}$ bands are observed. However, the intensities of the bands corresponding to vibrations of the hydrogen-bonded $\mathrm{sp}^{2}$ and $\mathrm{sp}^{3}$-hybridized carbon atoms are very low for both the source and UV-irradiated specimen \#2. The spectra of the source and UV-irradiated specimen \#2 also contain the bands corresponding to vibrations of the carbonyl group $\nu_{>\mathrm{C}=\mathrm{O}}\left(1626 \mathrm{~cm}^{-1}\right)$ and the hydroxyl group $\nu_{-\mathrm{OH}}\left(3434 \mathrm{~cm}^{-1}\right)$. As for the last band, unlike specimen $\# 1$, there is no long-wave shoulder associated with vibrations of the so-called related $\nu_{-} \mathrm{OH}$ group for it.

Let us analyze changes of the MWCNTs spectra under the influence of UV radiation in more details. But before that, we will make two assumptions on which our analysis will be based. First, the intensity of the bands corresponding to vibrations of different functional groups is proportional to the number of these groups. Second, the number of $\mathrm{C}=\mathrm{C}$ vibrations in the graphite layer and, therefore, the absolute intensity of the $\nu_{\mathrm{C}=\mathrm{C}}$ band do not change under the UV irradiation. However, the literature has the data on the disappearance of the line $\mathrm{C}=\mathrm{C}$ after the irradiation of CNTs with powerful UV for the time more than $20 \mathrm{~min}$. Due to a powerful UV irradiation, a part of the substance evaporates from the surface of the CNTs, which leads to a decrease in the intensity of the $\mathrm{C}=\mathrm{C}$ band. However, the conditions of UV irradiation in our studies are such that the number of $\mathrm{C}=\mathrm{C}$ connections is obviously unchanged. Therefore, it is logical to choose the relative intensity of the $\mathrm{C}=\mathrm{C}$ band as the unit of intensity.

In Table, we give the wave numbers corresponding to different functional groups and their intensities relative to the band intensity of the valence vibrations of $\mathrm{C}=\mathrm{C}$ atoms in the graphite layer. Figure 3 presents the diagrams of the ratio of relative intensities of the bands corresponding to vibrations of various functional groups before and after the UV irradiation for both specimens.

Wave numbers $\nu$ ' and relative intensities

$I / I_{\nu \mathrm{C}=\mathrm{C}}$ of the bands of IR spectra corresponding to different functional groups for specimens \#1 and $\# 2$ before and after the UV irradiation

\begin{tabular}{|c|c|c|c|c|c|}
\hline \multirow{2}{*}{$\begin{array}{c}\nu, \\
\mathrm{cm}^{-1}\end{array}$} & \multirow{2}{*}{$\begin{array}{l}\text { Functional } \\
\text { group }\end{array}$} & \multicolumn{2}{|c|}{ Specimen \#1 } & \multicolumn{2}{|c|}{ Specimen \#2 } \\
\hline & & $\begin{array}{c}\text { Source } \\
I / I_{\nu \mathrm{C}=\mathrm{C}}\end{array}$ & $\begin{array}{l}\text { After UV } \\
I / I_{\nu \mathrm{C}=\mathrm{C}}\end{array}$ & $\begin{array}{l}\text { Source } \\
I / I_{\nu \mathrm{C}=\mathrm{C}}\end{array}$ & $\begin{array}{l}\text { After UV } \\
I / I_{\nu} \mathrm{C}=\mathrm{C}\end{array}$ \\
\hline 1540 & $\nu_{\mathrm{C}=\mathrm{C}}$ & 1 & 1 & 1 & 1 \\
\hline 2926 & $\nu_{\mathrm{sp}^{2}-\mathrm{H}}$ & 0.75 & 2 & 0.2 & 0.8 \\
\hline 2853 & $\nu_{\mathrm{sp}^{3}-\mathrm{H}}$ & 0.325 & 1 & 0.2 & 0.7 \\
\hline 3224 & $\nu_{-} \mathrm{OH}($ related $)$ & 0.75 & 35 & 10 & 7 \\
\hline 1626 & $\nu_{>\mathrm{C}=\mathrm{C}}$ & 1.625 & 26 & 10 & 1.4 \\
\hline 1409 & $\delta_{-\mathrm{OH}}$ & 1 & 27 & - & - \\
\hline 1272 & $\nu_{\mathrm{C}-\mathrm{C}}$ & 1.015 & 20 & 2.3 & 2.5 \\
\hline 1053 & $\nu_{\mathrm{C}-\mathrm{C}}$ & 0.65 & 15 & & \\
\hline
\end{tabular}




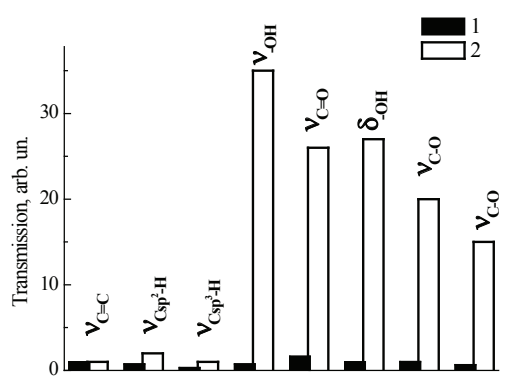

$a$

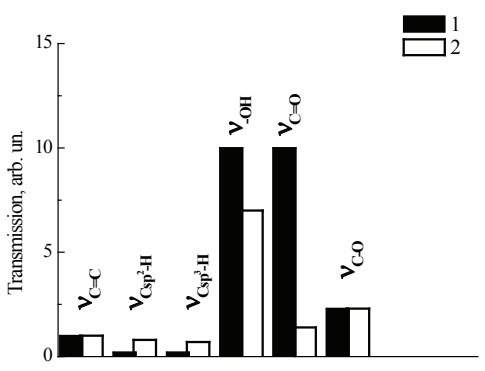

$b$

Fig. 3. Ratio of relative intensities of the bands corresponding to the various functional groups vibrations before and after UV irradiation for specimen \#1 (a) and specimen \#2 (b) before (1) and after (2) UV irradiation

As is seen from Table and Fig. 3 for specimen $\# 1$, the relative intensities of the bands corresponding to vibrations of carbon atoms in the graphite skeleton are approximately equal to the relative intensities of the bands corresponding to vibrations of the functional groups. For the spectrum of UV-irradiated specimen $\# 1$, there are practically no bands corresponding to vibrations of carbon atoms in the graphite skeleton $\left(\mathrm{C}=\mathrm{C}, \mathrm{C}_{\mathrm{sp}^{2}-\mathrm{H}}\right.$ and $\mathrm{C}_{\mathrm{sp}^{3}-\mathrm{H}}$ bands). This spectrum contains only bands corresponding to vibrations of the functional groups $\mathrm{OH},>\mathrm{C}=\mathrm{O}$, and $\mathrm{C}-\mathrm{O}$. The relative intensity of these bands in comparison with the intensity of the $\nu_{\mathrm{C}=\mathrm{C}}$ band increases almost thirty times. Thus, under the UV irradiation, the intense functionalization of the surface of specimen $(\# 1)$ is observed. Note that the intensities of the $\nu_{-\mathrm{OH}}$ are related, and $\nu_{>\mathrm{C}=\mathrm{O}}$ are correlated with each other. Obviously, this points to the fact that precisely carboxyl groups are formed on the surface of source MWCNTs under the UV irradiation.

A completely different situation is observed for specimen \#2 (MWCNTS with perfect structure). The first feature of the spectrum for specimen $\# 2$ is the small relative intensity of vibrations of the hydrogen-bonded $\mathrm{sp}^{2}$ - and $\mathrm{sp}^{3}$-hybridized carbon atoms in comparison with the intensity of the $\nu_{\mathrm{C}=\mathrm{C}}$ band. Obviously, this is due to a significantly smaller defect of the MWCNTs structure for specimens \#2, because, first of all, the attachment of hydrogen atoms to the carbon atoms by defects and crystallite boundaries occurs in graphite layers. For specimen $\# 2$, the relative intensities of the bands corresponding to vibrations of the functional groups, in particular, hydroxyl and carbonyl groups, are 10 times higher than the intensity of the band corre- sponding to vibrations of the carbon atoms in the graphite skeleton. After the UV irradiation, the relative intensities of the bands $\nu_{\mathrm{Csp}^{2}-\mathrm{H}}$ and $\nu_{\mathrm{Csp}^{3}-H}$ increase almost four times, while the relative intensities of the $\nu_{-\mathrm{OH}}$ and $\nu_{>\mathrm{C}=\mathrm{O}}$ bands decrease. Moreover, the relative intensity of the $\nu_{-} \mathrm{OH}$ band decreases only by $30 \%$, and relative intensity of the $\nu_{>\mathrm{C}=\mathrm{O}}$ band is decreased by 7 times. Herewith, the relative intensity of the $\nu_{\mathrm{C}-\mathrm{O}}$ band is almost unchanged. So, for specimen \#1 containing high-defect MWCNTs under the influence of UV radiation, the relative intensity of bands corresponding to vibrations of all functional groups is unambiguously increased. For specimen $\# 2$, which consists of MWCNTs with perfect structure, the processes occurring on the surface of the MWCNTs under the UV irradiation are much more complex.

Thus, the analysis of the IR spectra of MWCNTs with different degrees of structure perfection has revealed that the processes occurring on the surface of the CNTs under the UV irradiation are significantly dependent on the degree of structural perfection of MWCNTs. For MWCNTs with imperfection structure, the short-term UV irradiation resulted in a significant increase in the relative concentration of functional groups, in particular, hydroxyl and carbonyl groups and the C-O group. As is known, the UV irradiation leads to a partial conversion of oxygen contained in air to ozone. For MWCNTs with more perfect structure, the UV irradiation does not lead to the formation of new functional groups on the surface of CNTs. But, on the contrary, a part of the functional groups on the surface of MWCNTs is destroyed.

As is known, ozone is a strong oxidant, and its interaction with the surface of CNTs leads to the for- 
mation of a significant amount of oxygen-containing groups on it. This process obviously depends significantly on the degree of defectness in the graphite layer. When the defectness of the graphite layer is significant (the presence of broken bonds at the places of boundary defects), the process of attachment of functional groups to the surface of the CNT is intense. If the structure of the graphite layer is not defective (there are no broken bonds between the carbon atoms in the graphite layer), the short-term UV irradiation does not lead to a significant functionalization of the CNT surface.

\section{Conclusions}

Thus, the carried out investigations have shown that the short-term ultraviolet irradiation can cause a partial functionalization of the CNTs surface with oxygen-containing functional groups. The qualitative composition and the relative number of functional groups depend essentially on the degree of defectness of tubes and the state of their surface. The largest number of functional groups is observed for highly defective MWCNTs with a lot of torn chemical bonds. For MWCNTs with a perfect structure, the degree of functionality after the UV-irradiation is significantly smaller in comparison with defective MWCNTs. Moreover, the UV-irradiation of perfected MWCNTs leads to a decrease in the degree of their functionalization.

1. D.A. Usanov, A.V. Skripal', A.V. Romanov. Complex permittivity of composites based on dielectric matrices with carbon nanotubes. Tech. Phys. 56, 102 (2011).

2. S.H. Jeong, J. Ko, J. Park, W. Park. A sonochemical route to single-walled carbon nanotubes under ambient conditions. J. Am. Chem. Soc. 126, 15982 (2004).

3. K. Awasthi, A.S., O.N. Srivastava. Synthesis of carbon nanotubes. J. Nanosci. Nanotechnol. 5 (10), 1616 (2005).

4. D. Bikiaris, A. Vassiliou, K. Chrissafis, K.M. Paraskevopoulos, A. Jannakoudakis, A. Docoslis. Effect of acid treated multiwalled carbon nanotubes on the mechanical, permeability, thermal properties and thermo-oxidative stability of isotactic polypropylene. Polym. Degrad. Stabil. 93, 952 (2008).
5. V. Datsyuk, M. Kalyva, K. Papagelis, J. Parthenios, D. Tasis, A. Siokou, I. Kallitsis, C. Galiotis. Chemical oxidation of multiwalled carbon nanotubes. Carbon 46, 833 (2008).

6. J. Zhang, H. Zou, Q. Qing, Y. Yang, Q. Li, Z. Liu, X. Guo, Z. Du. Effect of chemical oxidation on the structure of single-walled carbon nanotubes. J. Phys. Chem. B 107, 3712 (2003).

7. M.N. Tchoul, W.T. Ford, G. Lolli, D.E. Resasco, S. Arepalli. Effect of mild nitric acid oxidation on dispersability, size, and structure of single-walled carbon nanotubes. Chem. Mater. 19, 5765 (2007).

8. V.E. Muradyan, E.A. Sokolov, S. Babenko, A. Moravsky. Microwave dielectric properties of composites modified by carbon nanostructures. Tech. Phys. 55, 242 (2010).

9. R. Zhang, A. Dowden, H. Deng, M. Baxendale. Conductive network formation in the melt of carbon nanotube/thermoplastic polyurethene composite. Compos. Sci. Technol. 69, 1499 (2009).

10. A. Naumenko, V. Yashchuk, V. Bliznyuk, S. Singamaneni. Peculiarities of Raman spectra of polyurethane/carbon nanotube composite. Eur. Phys. J. B 85, 120 (2012).

11. I.V. Ovsiienko, T.A. Len, L. Yu. Matzui, O.A. Golub, Yu.I. Prylutskyy, P.C. Eklund. The effect of thermal and chemical treatment on the structural and phase composition of nanocarbon materials. Materials Science and Engineering $C \mathbf{2 6}$ (5-7), 1180 (2006).

Received 09.10.19

I. Овсієнко, Т. Ленъ, Л. Мацуй,

О. Сиволожсъкий, Д. Шпилъка, Д. Наумова

ІНФРАЧЕРВОНА СПЕКТРОСКОПІЯ

ВУГЛЕЦЕВИХ НАНОТРУБОК ПІД ДІЄЮ

УЛЬТРАФІОЛЕТОВОГО ОПРОМІНЮВАННЯ

$\mathrm{P}$ е $з$ ю м е

В роботі розглядається можливість використання ультрафіолетового опромінювання для функціоналізації вуглецевих нанотрубок (ВНТ) з різним ступенем структурної досконалості. Для дослідження використовується метод інфрачервоної спектроскопії. Зміна кількості функціональних груп на поверхні ВНТ оцінюється за зміною відносної інтенсивності смуг інфрачервоного спектру, що відповідають коливанням функціональних груп на поверхні ВНT, у порівнянні з відносною інтенсивністю смуги, що відповідає коливанням атомів вуглецю в графітовому шарі. 